Open Journal of Gastroenterology and Hepatology
(ISSN:2637-4986)

\title{
Oral health status of patients with decompensated liver cirrhosis in two hospitals of Yaoundé Cameroon: A comparative study
}

\author{
Mathurin Pierre Kowo ${ }^{1,2}$, Alex Franklin Diffo', Marie Elvire Nokam Abena ${ }^{1}$, Larry Tangie \\ Ngek $^{1}$, Antonin Wilson Ndjitoyap Ndam ${ }^{1,3}$, Rose-Claire Bitha ${ }^{1}$, Firmin Ankouane Andoulo ${ }^{1,4}$ \\ ${ }^{1}$ Faculty of Medicine and Biomedical Sciences, University of Yaoundé I, Cameroon; ${ }^{2}$ University \\ Hospital Centre, Yaoundé, Cameroon; ${ }^{3}$ Yaoundé General Hospital, Yaoundé, Cameroon; ${ }^{4}$ Yaoundé \\ Central Hospital, Yaoundé, Cameroon
}

\section{ABSTRACT}

Background: Liver cirrhosis is an ultimate complication of all chronic liver diseases. The oral cavity especially the periodontium is affected by malnutrition, coagulation disorders, immunodeficiency which are some of the main features present in patients with liver cirrhosis. The aim of this study was to determine the prevalence and determinants of oral pathologies in patients with decompensated liver cirrhosis in two hospitals of Yaoundé Cameroon.

${ }^{*}$ Correspondence to Author:

Mathurin Pierre Kowo ${ }^{1,2}$

${ }^{1}$ Faculty of Medicine and Biomedical Sciences, University of Yaoundé I, Cameroon; ${ }^{2}$ University Hospital Centre, Yaoundé, Cameroon

Patients and Methods: This was a cross-sectional and analytHow to cite this article: ical study comparing the oral health status of decompensated liver cirrhotic patients in Yaoundé with sex and age ( \pm 3 years) matched healthy controls from the same area. We enrolled paMathurin Pierre Kowo, Alex Franklin Diffo, Marie Elvire Nokam Abena, Larry Tangie Ngek, Antonin Wilson Ndjitoyap Ndam, Rose-Claire Bitha, tients with liver cirrhosis (Child Pugh score greater than or equal to 7) and their corresponding healthy controls. For each participant, socio-demographic data, clinical data on liver cirrhosis and on oral examination were collected. Oral examination evaluated the level of oral hygiene, gingival index (GI), probing depth (PD) and Clinical attachment loss (CAL), determined and identified oral mucosal lesions. The mean Decayed-Missing-Filled-Teeth (DMFT) index and prevalence of dental caries were also determined. The groups were then compared with regards to periodontal oral mucosal and dental variables using chi square test and Mantel - Haenszel odds ratio was used to determine the strength of association between decompensated liver cirrhosis Firmin Ankouane Andoulo.Oral health status of patients with decompensated liver cirrhosis in two hospitals of Yaoundé Cameroon: A comparative study. Open Journal of Gastroenterology and Hepatology, $2021,4: 44$

and oral pathologies. The student's T-test was used to compare mean values of quantitative variables. A p-value $<0.05$ was statistically significant. 
Results: We included a total of 80 participants among which 40 liver cirrhotic patients and 40 sex and age ( \pm 3 years) matched controls. The mean age was $50.0( \pm 19.0)$ years for the cases and $52.4( \pm 17.9)$ years for the healthy controls. Hepatitis B virus (HBV) and Hepatitis C virus (HCV) were the main aetiology of liver cirrhosis representing $42.5 \%$ and $30 \%$ respectively and Child Pugh class B (65\% of cases) was the most represented stage of the disease. A number of past bucco-dental consultations was significantly less frequent in the cases than the controls (09 versus $18, p=0.03$ ). Over $80 \%$ of cases used an inappropriate brushing technique compared to $60 \%$ of controls and $55 \%$ of cases used toothbrushes and toothpaste compared to $85 \%$ controls $(p=0.09)$. A frequency of brushing at least twice daily was $42.5 \%$ in cases compared to $55 \%$ in controls $(p=0.19)$. Patients with decompensated liver cirrhosis had a significantly greater prevalence of periodontal disease than the controls $(95 \%$ versus $77.5 \%, p=0.013)$. In addition, they had greater mean $\mathrm{PI}(1.8( \pm 0.7)$ versus 1.6( \pm 0.5$), p=0.182)$, mean $\mathrm{Gl}$ index $(1.9( \pm 0.8)$ versus $1.3( \pm 0.64), p=0.004)$ and periodontal recession (77.5\% versus $47.5 \%$ ). Oral mucosal lesions and salivary lesions were more frequent in cirrhotic patients than in the healthy controls. These lesions include xerostomia (45\% versus $17.5 \%$, $p<0.001)$, oral candidiasis $(7.5 \%$ versus $0 \%, p=0.120)$, lichen planus $(17.5 \%$ versus $2.5 \%, p=$ $0.028)$, petechiae $(57.5 \%$ versus $5 \%, p<0.001)$, halitosis $(50 \%$ versus $7.5 \%, p<0.001)$ and sialadenitis $(17.5 \%$ versus $0 \%, p=0.006)$. Higher prevalence's of dental and mean DMFT index were found in cases than in controls. Factors associated with the development of oral pathologies in decompensated cirrhotic patients were oral consultations $(p=0.046)$, presence of cytolysis (OR $=2.58, p=0.042)$ and inadequate brushing technique $(p=0.004)$.

Conclusion: The prevalence of oral pathologies is higher in patients with decompensated liver cirrhosis than corresponding age-sex matched healthy controls.

Key words: decompensated liver cirrhosis; oral health status; Yaoundé

\section{INTRODUCTION}

The oral cavity is an essential part of the human body and generally represents an important source of information on the general state of an individual. The burden of oral pathologies continues to rise worldwide and especially in the developing world [1]. The number of people with untreated oral conditions rose from 2.5 billion in
1990 to 3.5 billion in 2015, with a $64 \%$ increase in disability adjusted life years due to oral conditions throughout the world ${ }^{\text {[2] }}$ with African countries being the most affected in the world. While most oral pathologies are primary, the others result from systemic communicable and non-communicable diseases among which; Human immunodeficiency virus (HIV) infection, 
diabetes mellitus, chronic kidney disease (CKD) and liver cirrhosis. Liver cirrhosis is defined as an irreversible hepatic architecture impairment resulting from progressive fibrosis and characterized by the development of regenerating nodules and a chronic sustained inflammatory response ${ }^{[3]}$. The global burden of liver cirrhosis varies across the world and numbers are even higher in most African countries where chronic hepatitis B and C are frequent. Generally decompensated cirrhosis presents with the signs of malnutrition, ascites, edema, esophageal varices, and coagulation disorders ${ }^{[4]}$. Several studies have been done on liver cirrhosis and oral pathologies and more specifically periodontitis and several hypothesis exists to explain the link between liver diseases and periodontitis such as the inflammatory nature of the two diseases, the defect of the microcirculation of the gingiva in liver disease patients which leads to more periodontal destruction, and the decrease in the function of the liver to clear bacteria which leads to more periodontal bacterial growth, the psychological factor and poorer oral hygiene practice of liver disease patients which leads to more periodontal destruction [5]. Few studies have been done in our setting to assess the influence of decompensated liver cirrhosis on oral health status of individuals thus justifying the need to determine the prevalence and identify the determinants of oral pathologies in patient with decompensated liver cirrhosis in two tertiary hospitals in Sub Saharan Africa.

\section{MATERIALS AND METHODS}

\section{Study design}

This was an analytical cross-sectional study carried out for a period of 8 months from November 2019 to July 2020 in two referral hospitals in Yaoundé (Yaoundé central hospital and the Yaoundé university teaching hospital). Our study population was made up of two groups; Group 1 (cases) made up of participants with decompensated liver cirrhosis and group 2 (control group) made up healthy sex-age( $\pm 3 y e a r s)$ matched participants accompanying patients all selected from the gastroenterology unit of the $\mathrm{YCH}$ and internal medicine units of YUTH .

Included in the group of cases were all patients suffering from liver cirrhosis (having a ChildPugh score greater than or equal to 7 , corresponding to the classes of Child-Pugh B and $\mathrm{C}$ ) present or being followed-up at the gastroenterology units of the $\mathrm{YCH}$ and $\mathrm{YUTH}$ at the time of study, patients with liver cirrhosis who gave their consent to take part in the study and at least 18 years of age. Were included in the control group all disease-free participants from the same hospital, sex-age ( \pm 3 years) matched with the cases. Were excluded from both groups, patients with incomplete medical records, patients with other underlined systemic diseases which could influence their oral health such as HIV, Diabetes, other diseases manifested by bone loss and even physiologic condition such as pregnancy, patients who had undergone periodontal treatment less than 6 months prior to the study and patients with less than $50 \%$ of the teeth present per sextant.

Participants were enrolled using a convenient non - randomized method. For each case, a corresponding sex-age $( \pm 3$ years $)$ matched control without any systemic disease and liver disease was also recruited. The sample size was estimated using the Schwartz formula using an estimated prevalence of oral pathologies in liver transplant patients of $96 \%$ giving a sample size of 59 participants.

Data collected included; socio-demographic (name, gender, age, level of education, profession), past medical history (current medication, any other chronic disease, alcohol intake, smoking status), history of the liver cirrhosis (the duration of the disease after diagnosis, follow-up, treatment), bucco-dental history (dental check-up, brushing tool, brushing frequency, brushing technique).

Oral and periodontal clerking was done on a dental chair inclined at about $120^{\circ}$ to the horizontal (If not available, the clerking was done on a chair with the patient's head inclined at $45^{\circ}$ 
to back under a good lightening condition) in the odontostomatology units of both hospitals under the supervision of a dental physician. The oral status of the participants was assessed by proceeding as follows; dividing the oral cavity into 6 sextants (recommendation of the WHO), all the teeth and their different surfaces were carefully examined. Clerking assessed the state of oral mucosa, and periodontal status (dental plaque, dental calculus, inflammation of the gingiva, clinical attachment loss, presence or absence of periodontal pockets and their characteristics, tooth mobility) using a well calibrated periodontal probe, dental mirror, probe $\mathrm{N}^{\circ} 15$ under appropriate lightening.

The level of oral hygiene was assessed using the plaque index score by Sillness and Loe (1964) and described by grouping the score per participants into 04 categories ;excellent oral hygiene: Score $=0$,good oral hygiene: score $=$ $0.1-0.9$, moderate oral hygiene: score $=1.0-$ 1.9 ,poor oral hygiene: score $=2-3$. Gingivitis was assessed using the gingival index (gingival inflammation index) by Loe $\mathrm{H}$ and Silness $\mathrm{J}$ (1963) and described as follows; no inflammation $=0$, mild gingivitis $=0.1-1.0$, moderate gingivitis $=1.1-2.0$, severe gingivitis $=2.1-3.0$. Periodontal status of participants was evaluated using the probing depth $(0-3 \mathrm{~mm}$ $=$ normal and $\geq 4 \mathrm{~mm}=$ presence of periodontal pocket) clinical attachment loss (CAL). Tooth mobility was assessed using Mulhemann's score and described as follows; $0=$ Ankylosis, $1=$ Physiologic mobility distinguishable between two fingers, $2=$ Mobility in the transverse direction visible by naked eyes, $3=$ Mobility in the transverse direction visible by naked eyes $>1 \mathrm{~mm}, 4=$ Mobility in all directions. The number of permanent teeth decayed, missing teeth due to dental caries and filled of an individual was assessed using the DMFT index and described as follows; very low level when 0 $<$ DMF index $<1.1$, low level when $1.2<$ DMF index $<2.6$, average level when $2.7<D M F$ index $<4.4$, high level when $4.5<\mathrm{DMF}$ index $<6.5$, very high level when DMF index $>6.5$.
The diagnosis of liver cirrhosis was based on clinical and biological signs of hepatocellular insufficiency and portal hypertension (ascites, hepatic encephalopathy, jaundice of the eye, coagulopathy, asterixis, foetor hepaticus, splenomegaly; decrease in prothrombin time, factor $V$, and increase in the INR), ultrasonographic signs of liver cirrhosis and endoscopic signs of portal hypertension. This ultrasonographic signs included irregular liver outlines, heterogeneous echo structures, enlarged portal veins and presence of collateral circulation.

\section{Study setting}

This study was carried out in the gastroenterology unit of the Yaoundé Central Hospital $(\mathrm{YCH})$ and the internal medicine unit of the Yaoundé University Teaching Hospital (YUTH). These are tertiary hospitals which serve as referral centres and teaching hospitals for medical students nationwide. They have several outpatient and hospitalization wards. The Yaoundé central Hospital is made up of six specialty units, namely surgical unit and specialties, Intensive care unit, gynaecological and obstetrical unit, internal medicine and specialties unit. The internal medicine and specialty unit is made of several sub units among which the gastroenterology unit. This unit has two specialists, one being a professor and head of the unit. The consultation of out-patients runs from Monday to Thursday, two days per consultant.

The Yaoundé University Teaching Hospital is the main teaching hospital of the Faculty of Medicine and Biomedical Sciences. It is made up of several units among which that of internal medicine and specialties. The internal medicine unit in the YUTH has 4 wards, a general male and female ward having 8 beds each and 2 private rooms. The gastroenterology staff is made of three gastroenterologist, among which a professor and head of the internal medicine unit. There are averagely 3 or 4 residents and interns on internship. The outpatient department runs from Monday to Friday. Gastroenterology 
consultations hold from Monday to Friday, two days per consultant.

\section{Data Analysis}

Data was entered using CSpro (Census and Survey Processing system) version 7.1 and analyzed using IBM-SPSS (International Business Machine- Statistical Package for Social Sciences) version 21.0. Univariate analyses for continuous variables were presented as mean \pm standard deviation (SD), while categorical variables were presented using frequencies and percentages. The Student's Ttest was used to compare the mean values of two quantitative variables Chi test was used to compare proportions of qualitative variables. A test was considered statistically significant for a $p$-value $<0.05$.odds ratios were used to assess the strength of association between variables.

\section{Ethical considerations}

Ethical approval was obtained from the Institutional Review Board of the Faculty of Medicine and Biomedical Sciences of the University of Yaoundé 1. We also obtained administrative approval from the General Managers of the $\mathrm{YCH}$ and $\mathrm{YUTH}$.

Table I: Socio-demographic characteristics

\begin{tabular}{|c|c|c|c|c|c|}
\hline \multirow[b]{2}{*}{ Variables } & \multicolumn{2}{|l|}{ Cases } & \multicolumn{2}{|l|}{ Controls } & \multirow{2}{*}{ p-value } \\
\hline & $\mathbf{N}$ & $\%$ & $\mathbf{N}$ & $\%$ & \\
\hline \multicolumn{6}{|l|}{ Age (years) } \\
\hline Mean age \pm SD (years) & $50.0 \pm 19.0$ & & $52.4 \pm 17.9$ & & \\
\hline - $<20$ & 01 & 2.5 & 01 & 2.5 & \\
\hline - $\quad[20-40[$ & 17 & 42.5 & 14 & 35 & 0.749 \\
\hline - $\quad[40-60[$ & 08 & 20 & 09 & 22.5 & \\
\hline - $\quad[60-80[$ & 11 & 27.5 & 13 & 32.5 & \\
\hline - $\quad \geq 80$ & 03 & 7.5 & 03 & 7.5 & \\
\hline \multicolumn{6}{|l|}{ Sex } \\
\hline - Male & 29 & 72.5 & 29 & 72.5 & \\
\hline - Female & 11 & 27.5 & 11 & 27.5 & 0.599 \\
\hline Educational level & & & & & \\
\hline - No formal education & 7 & 17.5 & 13 & 32.5 & \\
\hline - Primary & 4 & 10 & 6 & 15 & \\
\hline - Secondary & 17 & 42.5 & 7 & 17.5 & \\
\hline - Higher & 12 & 30 & 14 & 35 & \\
\hline
\end{tabular}

Table I: distribution of cases with respect to the duration, etiology and stage of the liver disease

\begin{tabular}{|c|c|c|}
\hline Variables & Absolute frequency $(n)$ & Percentage (\%) \\
\hline \multicolumn{3}{|c|}{ Duration after diagnosis (months) } \\
\hline - $\leq 24$ & 24 & 60 \\
\hline - $>24$ & 16 & 40 \\
\hline \multicolumn{3}{|l|}{ Aetiology } \\
\hline - $\mathrm{HBV}$ & 17 & 42.5 \\
\hline - $\mathrm{HBV}+\mathrm{HDV}$ & 4 & 10 \\
\hline HCV & 12 & 30 \\
\hline - Alcohol & 7 & 10 \\
\hline $\begin{array}{c}\text { Stage of liver disease } \\
\text { - Child Pugh B }\end{array}$ & 26 & 65 \\
\hline - Child Pugh C & 14 & 35 \\
\hline
\end{tabular}




\section{RESULTS}

A total of 80 participants (58 males and 22 females) were included in the study, 40 liver cirrhotic patients (29 males and 11 females) and 40 sex-age ( \pm 3 years) matched controls. The mean age was $50.0( \pm 19.0)$ years for the cases and $52.4( \pm 17.9)$ years for the healthy controls (Table I). Hepatitis B virus (HBV) and Hepatitis $C$ virus $(\mathrm{HCV})$ were the main aetiology of liver cirrhosis representing $42.5 \%$ and $30 \%$ respectively and Child Pugh class B was the most represented stage of the disease in $65 \%$ of cases (Table II). A past medical history of buccodental consultations was significantly less frequent in the cases than the controls $(09$ versus $18, p=0.03$ ) (Table III). The vertical and horizontal brushing techniques were significantly different in the two groups as the vertical technique was more frequent in the controls (20\% versus $40 \%, p=0.035$ ) and the horizontal technique in the cases $(55 \%$ versus $10 \%, p=$ 0.002) (Table III).

Table II: Distribution of study population with respect to the past dental history and oral hygiene

\begin{tabular}{|c|c|c|c|c|c|}
\hline \multirow[b]{2}{*}{ Variables } & \multicolumn{2}{|c|}{ Cases } & \multicolumn{2}{|c|}{ Controls } & \multirow[b]{2}{*}{ P-value } \\
\hline & $\mathbf{n}$ & $\%$ & $\mathbf{N}$ & $\%$ & \\
\hline \multicolumn{6}{|l|}{ Bucco-dental consultations } \\
\hline Yes & 09 & 22.5 & 18 & 45 & \multirow[b]{2}{*}{0.03} \\
\hline No & 31 & 77.5 & 22 & 55 & \\
\hline \multicolumn{6}{|c|}{ Frequency of tooth brushing per day } \\
\hline Once & 23 & 57.5 & 18 & 45 & \multirow[b]{2}{*}{0.186} \\
\hline Twice or more & 17 & 42.5 & 22 & 55 & \\
\hline \multicolumn{6}{|l|}{ Brushing tools } \\
\hline Tooth brush only & 13 & 32.5 & 06 & 15 & \multirow[b]{2}{*}{0.098} \\
\hline Tooth brush + tooth paste & 22 & 55 & 34 & 85 & \\
\hline Dental floss & 1 & 2.5 & 0 & 0 & - \\
\hline Tooth brush and floss & 2 & 5 & 0 & 0 & - \\
\hline Mouth wash & 1 & 2.5 & 0 & 0 & - \\
\hline Others & 1 & 2.5 & 0 & 0 & - \\
\hline \multicolumn{6}{|l|}{ Brushing technique } \\
\hline Vertical (1) & 08 & 20 & 16 & 40 & 0.035 \\
\hline Horizontal (2) & 22 & 55 & 08 & 10 & 0.002 \\
\hline Circular & 04 & 10 & 03 & 07.5 & 0.635 \\
\hline$(1)+(2)$ & 06 & 15 & 13 & 32.5 & 0.215 \\
\hline
\end{tabular}

$n=$ Absolute frequency $\%=$ Relative frequency

Table III Periodontal diseases in the population

\begin{tabular}{lllll}
\hline Periodontal disease & $\begin{array}{l}\text { Cases } \\
\mathbf{n}(\%)\end{array}$ & $\begin{array}{l}\text { Controls } \\
\mathbf{n}(\%)\end{array}$ & OR[95\%Cl] & p -value \\
\hline Gingivitis & $\mathbf{1 1 ( 2 7 . 5 )}$ & $9(22.5)$ & & \\
Periodontitis & $\mathbf{2 7 ( 6 7 . 5 )}$ & $22(55)$ & & \\
Periodontal disease & $\mathbf{3 8 ( 9 5 . 0 )}$ & $31(77.5)$ & $\mathbf{2 . 4}[1.8-4.9]$ & $\mathbf{0 . 0 1 3}$ \\
\hline
\end{tabular}

Table V: Distribution of the sample with respect to the mean $\mathrm{PI}$ and GI

\begin{tabular}{llll}
\hline Variables & Cases & Controls & P-value \\
\hline Plaque index & $1.82( \pm 0.66)$ & $1.61( \pm 0.50)$ & 0.182 \\
Gingival index & $1.94( \pm 0.83)$ & $1.32( \pm 0.64)$ & $\mathbf{0 . 0 0 4}$ \\
\hline
\end{tabular}


Table IV: distribution of study population with respect to periodontal recession

\begin{tabular}{|c|c|c|c|c|}
\hline \multirow{2}{*}{ Variables } & \multicolumn{2}{|c|}{ Cases } & \multicolumn{2}{|c|}{ Controls } \\
\hline & $\bar{n}$ & $\%$ & $n$ & $\%$ \\
\hline \multicolumn{5}{|l|}{ Recession } \\
\hline Class 1 & 9 & 22.5 & 19 & 47.5 \\
\hline Class 2 & 16 & 40 & 12 & 30 \\
\hline Class 3 & 13 & 32.5 & 09 & 17.5 \\
\hline Class 4 & 2 & 5 & 0 & 0 \\
\hline
\end{tabular}

$n=$ absolute frequency

$\%=$ relative frequency

Eighty per cent of cases used an inappropriate brushing technique compared to $60 \%$ of controls and $55 \%$ of cases used tooth brushes and tooth paste compared to $85 \%$ controls. Forty two point five per cent of cases had a frequency of brushing of at least twice daily compared to $55 \%$ of controls (Table III). Patients with decompensated liver cirrhosis had a significantly greater prevalence of periodontal disease than the controls $(95 \%$ versus $77.5 \%, p=0.013)$ (Table IV). In addition, they had greater mean plaque indices $(\mathrm{PI})(1.8( \pm 0.7)$ versus 1.6 $( \pm 0.5), \mathrm{p}$ $=0.182)$, mean gingival indices $(\mathrm{Gl})$ index $(1.9( \pm 0.8)$ versus $1.3( \pm 0.64), p=0.004)$ (table $V)$ and periodontal recession $(77.5 \%$ versus $47.5 \%)$ (Table VI). Oral mucosal lesions and salivary affections were more frequent in cirrhotic patients than in the healthy controls.
These lesions included cervical lymphadenopathies $(7.5 \%$ versus $2.5 \%, p=$ $0.308)$, xerostomia $(45 \%$ versus $17.5 \%, p$ $<0.001)$, oral candidiasis $(7.5 \%$ versus $0 \%, p=$ $0.120)$, lichen planus $(17.5 \%$ versus $2.5 \%, p=$ $0.028)$, petechiae $(57.5 \%$ versus $5 \%, p<0.001)$, halitosis $(50 \%$ versus $7.5 \%, p<0.001)$ and sialadenitis $(17.5 \%$ versus $0 \%, p=0.006)$ (table VII). Higher prevalence's of dental and mean DMFT index were found in cases than in controls $(5.1 \pm 3.8)$ versus $4.9 \pm 3.8), p=0.685)$ (Table VIII). Factors associated with the development of oral pathologies in decompensated cirrhotic patients were oral consultations $(p=0.046)$, presence of cytolysis ( $O R=2.58, p=0.042)$ and inadequate brushing technique $(\mathrm{p}=$ 0.004)(Table IX)(Table X).

Table V: Distribution of study population with respect to lymph nodes, oral mucosal and salivary glands lesions

\begin{tabular}{lllll}
\hline \multirow{2}{*}{ Variables } & Cases & Controls & \multirow{2}{*}{ OR [95\%Cl] } & p- value \\
\cline { 2 - 4 } & $\mathbf{n}(\%)$ & $\mathbf{n}(\%)$ & $1.2[-1.2-3.7]$ & 0.308 \\
Lymph nodes & $3(7.5)$ & $1(2.5)$ & $\mathbf{2 . 7}[1.9-3.6]$ & $<0.001$ \\
Xerostomia & $18(45)$ & $03(17.5)$ & - & 0.120 \\
Oral candidiasis & $03(7.5)$ & $0(0)$ & $\mathbf{2 . 1}[1.0-5.3]$ & $\mathbf{0 . 0 2 8}$ \\
Lichen planus & $7(17.5)$ & $1(2.5)$ & $\mathbf{3 . 3}[1.7-4.8]$ & $<0.001$ \\
Petechiae & $23(57.5)$ & $2(5)$ & $\mathbf{2 . 9}[1.8-5.3]$ & $<0.001$ \\
Halitosis & $20(50)$ & $3(7.5)$ & - & $\mathbf{0 . 0 0 6}$ \\
Sialadenitis & $7(17.5)$ & $0(0)$ & - & \\
\hline
\end{tabular}

$n=$ Absolute frequency, $\%=$ Relative frequency, $O R=$ Odds Ratio $\mathrm{Cl}=$ Confidence Interval

Table VIII: prevalence of dental caries and DMFT index

\begin{tabular}{llll}
\hline Variables & $\begin{array}{l}\text { Cases } \\
\mathbf{n}(\%)\end{array}$ & $\begin{array}{l}\text { Controls } \\
\mathbf{n}(\%)\end{array}$ & $\mathbf{p}$ - value \\
\hline Dental caries & $\mathbf{3 6}(\mathbf{9 0 . 3})$ & $33(85.1)$ & 0.366 \\
DMFT index (mean \pm SD) & $4.9( \pm 3.8)$ & $\mathbf{5 . 1}( \pm \mathbf{3 . 8})$ & 0.685 \\
\hline
\end{tabular}


Table IX: Factors associated with periodontal diseases

\begin{tabular}{|c|c|c|c|c|}
\hline Variables & Patients with PD & Patients without PD & OR[95\%Cl] & $P-$ value \\
\hline & n (\%) & n (\%) & & \\
\hline \multicolumn{5}{|l|}{ Sex } \\
\hline Males & $27(67.5)$ & $11(27.5)$ & & \multirow{2}{*}{0.521} \\
\hline Females & $02(5)$ & $0(0)$ & - & \\
\hline \multicolumn{5}{|l|}{ Brushing technique } \\
\hline Vertical & $3(7.5)$ & $1(2.5)$ & \multirow{2}{*}{$1.3[0.6-2.4]$} & \multirow[b]{2}{*}{0.958} \\
\hline Others & $25(62.5)$ & $11(27.5)$ & & \\
\hline \multicolumn{5}{|l|}{ Dental check-up } \\
\hline Yes & 7 (17.5) & $2(5)$ & & \\
\hline No & $31(77$ & $0(0)$ & - & 0.046 \\
\hline \multicolumn{5}{|l|}{ Alcohol intake } \\
\hline Yes & $26(65)$ & $0(0)$ & & \\
\hline No & $12(30)$ & $2(5)$ & - & 0.117 \\
\hline \multicolumn{5}{|l|}{ Smoking } \\
\hline Yes & $11(27.5)$ & $0(0)$ & & \\
\hline No & $27(67.5)$ & $2(5)$ & - & 0.521 \\
\hline \multicolumn{5}{|l|}{ ALT level } \\
\hline Elevated & $31(77.5)$ & $2(5)$ & \multirow[b]{2}{*}{$2.9[1.8-3.5]$} & \multirow[b]{2}{*}{0.042} \\
\hline Normal & $6(17.5)$ & $1(2.5)$ & & \\
\hline Mean age \pm SD (years) & $48.9( \pm 18.7)$ & $49.0( \pm 25.7)$ & - & 0.862 \\
\hline \multicolumn{5}{|c|}{$n=$ absolute frequency, $O R=$ Odds ratio, $\%=$ relative frequency, $\mathrm{Cl}=$ Confidence Interval $P D=$ Periodontal diseas } \\
\hline \multicolumn{5}{|c|}{ Table X: Factors associated with dental caries } \\
\hline Variables & $\begin{array}{l}\text { Patients with } \\
\text { dental caries }\end{array}$ & $\begin{array}{l}\text { Patients without } \\
\text { dental caries }\end{array}$ & OR[95\% Cl] & $P$ - value \\
\hline & n (\%) & n (\%) & & \\
\hline \multicolumn{5}{|l|}{ Sex } \\
\hline Males & $26(65)$ & $03(7.5)$ & \multirow{3}{*}{$0.14[0.11-2.52]$} & \multirow[b]{2}{*}{0.700} \\
\hline Females & $10(25)$ & $01(2.5)$ & & \\
\hline \multicolumn{4}{|l|}{ Brushing technique } & \\
\hline Vertical & $04(10)$ & $05(12.5)$ & \multirow[b]{2}{*}{$2.4[1.3-4.4]$} & \multirow[b]{2}{*}{0.004} \\
\hline Others & $19(47.5)$ & $12(30)$ & & \\
\hline \multicolumn{5}{|l|}{ Dental check-up } \\
\hline Yes & 7 (17.5) & $02(5)$ & \multirow[b]{2}{*}{$1.4[-0.7-3.6]$} & \multirow[b]{2}{*}{0.213} \\
\hline No & $29(72.5)$ & $02(5)$ & & \\
\hline \multicolumn{5}{|l|}{ Xerostomia } \\
\hline Yes & $16(40)$ & $02(5)$ & \multirow{3}{*}{$0.2[-1.8-2.3]$} & \\
\hline No & $20(50)$ & $02(5)$ & & 0.617 \\
\hline Mean age \pm SD (years) & $54.3( \pm 25.6)$ & $48.4( \pm 18.5)$ & & 0.566 \\
\hline
\end{tabular}

$n=$ absolute frequency $\%=$ relative frequency $O R=$ Odds ratio $\mathrm{Cl}=$ Confidence Interval

\section{DISCUSSION}

This study sought to determine the prevalence and determinants of decompensated liver cirrhosis on the oral health status of patients in two hospitals of Yaoundé. A total of 80 participants (58 males and 22 females) were included in the study, 40 liver cirrhotic patients (29 males and 11 females) and 40 sex-age $( \pm 3$ years) matched controls. The mean age was $50.0( \pm 19.0)$ years for the cases and $52.4( \pm 17.9)$ years for the healthy controls thus a relatively young population for both cases and controls. Viral hepatitis $\mathrm{B}$ and $\mathrm{C}$ were the main aetiology of liver cirrhosis representing $42.5 \%$ and $30 \%$ respectively and this is consistent with existing literature reporting Cameroon as being an endemic region for these viruses $[6,7]$

A past medical history of bucco-dental consultations was significantly less frequent in the cases than the controls (09 versus 18, $p=$ 
0.03). The vertical and horizontal brushing techniques were significantly different in the two groups as the vertical technique was more frequent in the controls $(20 \%$ versus $40 \%, p=$ 0.035 ) and the horizontal technique in the cases $(55 \%$ versus $10 \%, p=0.002)$. Oral hygiene and oral hygiene practices are influenced by individual culture and believes. Tooth brushing twice daily with toothbrush and fluorinated toothpaste is recommended by dentist to promote oral health and prevent oral pathologies. Only $30 \%$ of the sample used the correct brushing technique (vertical technique) among which $10 \%$ for the cases and $20 \%$ for the controls and $31.25 \%$ brushed their teeth at least twice daily. This deviation from the standards observed in both groups could be explained by the low level of sensitization on oral hygiene in our setting and also due to the fact that brushing technique is mostly taught and adapted to every individual during the annual session of dental check-up. Only $33.75 \%$ of participants reported to have ever consulted an oral practitioner as such deviation from established norms could account for these findings.

Patients with decompensated liver cirrhosis had a significantly greater prevalence of periodontal disease than the controls ( $95 \%$ versus $77.5 \%, p$ $=0.013$ ) (Table IV). In addition, they had greater mean plaque indices ( $\mathrm{Pl})(1.8( \pm 0.7)$ versus $1.6( \pm 0.5), p=0.182)$, mean gingival indices (Gl) index $(1.9( \pm 0.8)$ versus $1.3( \pm 0.64), p=0.004)$ (table $\mathrm{V})$ and periodontal recession $(77.5 \%$ versus $47.5 \%$ ) (Table VI). Differences in the prevalence of plaque index among cases and controls could be explained by several factors; the brushing technique used by cases wasn't appropriate as only $20 \%$ used the vertical method compared to $40 \%$ among controls. A bad brushing technique doesn't enable good dental hygiene control hence an accumulation of dental plaque. Secondly, a greater proportion of cases reported decreased salivary flow compared to the controls ( $45 \%$ vs $17.5 \%$ ) which tends to increase accumulation of plaque on the teeth. Stress provoked by the awareness of the health condition can cause a number of behavioral changes causing the patient to neglect a certain number of basic hygiene principles such as oral hygiene ${ }^{[5]}$. The above factors coupled with the immunocompromised condition caused by the decompensated liver cirrhosis creates conditions that favor the activity of bacteria and hence plaque formation. These findings are consistent with those of Di Profio et al. ${ }^{[8]}$ in Brazil in 2018 , Costa et al ${ }^{[9]}$ in Brazil in 2019 who found higher mean plaque index among cirrhotic cases than their corresponding controls.

The mean gingival indices (GI) index was significantly higher among cases than controls $(1.9( \pm 0.8)$ versus $1.3( \pm 0.64), p=0.004)$ (table V). This finding is a reflection of the relationship between poor oral hygiene and periodontal lesion. The presence of thrombocytopenia in the cases can also favor gingivitis during inadequate brushing.

Cases had a twofold risk of having periodontal disease than their corresponding controls (table IV) $\mathrm{OR}=2.4[1.8-4.9] \quad(p=0.013)$. The high prevalence of periodontitis in cases can be explained by the several factors such as poor oral hygiene as illustrated by higher mean plaque and calculus indices and biological factors among cirrhotic (cases) patients in this study. Similar higher prevalence's have been reported by several authors among cirrhotic patients when compared to their corresponding controls ${ }^{[10,8,9,11,12]}$.

Oral mucosal lesions found to be associated with decompensated liver cirrhosis were halitosis, petechiae, lichen planus, oral candidiasis and xerostomia(table VII).

Cases had a 2.9fold risk of having halitosis than controls $(\mathrm{OR}=2.9[1.6-5.3]$, p-value $<0.001)$. This could be explained by the presence of foetor hepaticus among cases characterized by the presence of excess dimethylsulphide and trimethylamine as well as the low level of oral hygiene in cases compared to controls leading to a greater mean calculus index and 
periodontitis which are the first causes of halitosis in general ${ }^{[13,14]}$.

Cases had a 2.7 risk of experiencing a decrease in saliva flow as compared to their corresponding controls $\mathrm{OR}=2.7[1.9-3.6]$ ( $45 \%$ versus $7.5 \%$, $\mathrm{p}=<0.001)$. This decrease in saliva flow can be explained by the use of diuretics to manage ascites in these patients and hepatitis $C$ virus as a major cause of cirrhosis in our setting which is known to be associated with the pathogenesis of Sjögren-like sialadenitis ${ }^{[15-17]}$.

Cases equally had a 3.3 fold risk of having petechiae than their corresponding controls $\mathrm{OR}=3.3[1.7-4.8](p<0.001)$. Low prothrombin time which is one of the main characteristic features of hepatocellular insufficiency in liver cirrhosis and thrombocytopenia a feature of portal hypertension could explain this finding.

Concerning lichen planus, cirrhotic patients had a 3fold risk of having lichen planus than controls with an $\mathrm{OR}=2.1$. Several studies suggest an association between lichen planus and hepatitis $C$ virus [15-18]. This could explain the high prevalence of lichen planus among our cases as $30 \%$ had HCV as the presumed baseline etiology for liver cirrhosis.

The high proportion of xerostomia, the low level of oral hygiene and the immunocompromised state of cases can explain the greater proportion of oral candidiasis in cases $(7.5 \%)$ than in controls ${ }^{[19]}$.

The high proportions of dental caries and greater mean DMFT index in the cases than the controls can be explained by the low level of dental check-up, poorer oral hygiene, inappropriate brushing technique and decreased saliva flow in this group of participants.

Inadequate brushing technique, lack of oral check-up and high level of ALT were found to be associated with the development of oral pathologies after bivariate analysis with respective p-values of $0.046,0.004$ and 0.042 . Participants with an inadequate brushing technique had a 2.4 fold risk of having an oral pathology than their corresponding controls with an OR of 2.4 [1.3 - 4.3].

The association between an inadequate brushing technique and oral pathologies is obvious giving that in this study $77.5 \%$ of the cases used an inadequate technique other than vertical technique $(22.5 \%)$ which is the most recommended. Indeed, good oral hygiene provided by an appropriate brushing technique is a necessary requirement to maintain an excellent oral health. Adequate tooth brushing helps reduce the quantity of plaque (microbial flora) thereby reducing the risk of developing periodontal diseases and dental caries.

An elevated level of serum enzyme Alanine aminotransferase (ALT) was also associated with the presence of periodontitis. This can be explained by the fact that bone-resorbing cytokines such as IL-1 $\beta$, TNF- $\alpha$, IL- 6 , and RANKL are produced in reaction to bacterial infections and induce alveolar bone loss (ABL) [20]. Since the degree of ABL could reflect integrated history of inflammation, it was expected to be associated with hepatic dysfunctions.

\section{Limits of the Study}

The study revealed an association between decompensated and oral pathologies represented by a higher prevalence of the latter in the cases than in the controls. Despite the link observed, a cross-sectional analytic study doesn't really give the sequence of appearance of those pathologies hence for more precisions the necessity of a longitudinal study.

The main difficulty encountered during our study was due to the outbreak of COVID-19 pandemic which scared the participants limiting our sample size giving that most patients refused the oral examination

\section{Conclusion}

The prevalence of oral pathologies is higher in liver cirrhosis patients than in controls $(95 \%$ versus $77.5 \%$ ). Liver cirrhosis patients have twofold risk of developing periodontitis than controls. The most frequent oral lesions 
associated with liver cirrhosis were xerostomia, lichen planus, petechiae, halitosis and sialadenitis. The factors associate with oral pathologies in liver cirrhosis patients are presence of oral clerking, vertical brushing technique and liver cytolysis. Patients with liver cirrhosis had poor oral health practices and oral hygiene than corresponding controls.

\section{DECLARATIONS}

\section{Ethics approval and consent to participate}

Ethical approval was obtained from the Institutional Review Board of the Faculty of Medicine

and Biomedical Sciences of the University of Yaoundé 1.1 Number 347/UY1/FMSB/VDRC/DAASR/CSP. We also obtained administrative approval from the General Managers of the $\mathrm{YCH}$ and $\mathrm{YUTH}$

For the purpose of confidentiality, participant's data were processed using specific unique identifiers

\section{Consent for publication}

Not applicable

\section{Availability of data and material}

The datasets generated during the current study are available from the corresponding author on request.

\section{Competing Interests}

The authors declare that they have no competing interests.

\section{Funding}

None

\section{Authors Contributions}

Authors MPK, AFD, MENA, FAA, AWNN, RCB contributed to the study design, wrote the research protocol, and contributed in data collection. Authors AFD and LT contributed in data analysis and editing the first draft of the manuscript. Authors MPK, and FAA supervised all the activities and approved the final version to be submitted for publication. All authors have read and approved the manuscript.
Not applicable

\section{REFERENCES}

[1]. Petersen PE, Bourgeois D, Ogawa H, EstupinanDay S, Ndiaye C. The global burden of oral diseases and risks to oral health. Bull World Health Organ. 2005;83(9):661-96.

[2]. Kassebaum NJ, Smith AGC, Bernabé E, Fleming TD, Reynolds AE, Vos T et al. Global, Regional, and National Prevalence, Incidence, and Disability-Adjusted Life Years for Oral Conditions for 195 Countries, 1990-2015: A Systematic Analysis for the Global Burden of Diseases, Injuries, and Risk Factors. J Dent Res. 2017;96(4):380-7

[3]. Zamora Nava LE, Aguirre Valadez J, ChávezTapia NC, Torre A. Acute-on-chronic liver failure: a review. Ther Clin Risk Manag. 2014;10(6):295303

[4]. Jankowska I, Neuhoff-Murawska J, Socha P, Pawllowska J, Socha J. Clinical aspects of nutrition in children with chronic cholestasis-on the basis of a selected case. Gastroenterol Rev Gastroenterol. 2008;3(3):139-42.

[5]. Elhassan AT, Peeran SW. The Linking Mechanisms Between Liver and Periodontal Diseases. EC dental science. 2016;4(2)758-66

[6]. Bilounga Ndongo C, Eteki L, Siedner M, Mbaye R, Chen J, Ntone $\mathrm{R}$, et al. Prevalence and vaccination coverage of Hepatitis $B$ among healthcare workers in Cameroon: A national seroprevalence survey. J Viral Hepat. Wiley Online Library; 2018;25(12):1582-7.

[7]. Bigna JJ, Amougou MA, Asangbeh SL, Kenne AM, Noumegni SRN, Ngo-Malabo ET, et al. Seroprevalence of hepatitis B virus infection in Cameroon: a systematic review and metaanalysis. BMJ Open. British Medical Journal Publishing Group; 2017;7(6):p12.

[8]. Di Profio B, Inoue G, Marui VC, de França BN, Romito GA, Ortega KL, et al. Periodontal status of liver transplant candidates and healthy controls. J Periodontol. 2018;89(12):1383-9.

[9]. Costa FO, Lages EJP, Lages EMB, Cota LOM. Periodontitis in individuals with liver cirrhosis: $A$ case-control study. J Clin Periodontol. oct 2019;46(10):991-8.

[10]. Bisse NAM. Aspects épidémiologiques et cliniques des parodontopathies sur cirrhose du foie au CHUY et HGY. Université de Yaoundé I. Faculté de Médecine et des Sciences Biomédicales ; 2015, p106 [cité 10 juill 2020]. Disponible sur: https://www.hsd fmsb.org/index.php/hsd/thesis/view/220.

\section{Acknowledgments}


[11]. Lins L, Bittencourt PL, Evangelista MA, Lins R, Codes L, Cavalcanti AR, et al. Oral Health Profile of Cirrhotic Patients Awaiting Liver Transplantation in the Brazilian Northeast. Transplant Proc. mai 2011;43(4):1319-21. 43.

[12]. Santos PS da S, Fernandes KS, Gallottini MHC. Assessment and management of oral health in liver transplant candidates. J Appl Oral Sci. Faculdade De Odontologia De Bauru - USP; 2012;20(2):241-5

[13]. Mitchell S, Ayesh R, Barrett T, Smith R. Trimethylamine and foetor hepaticus. Scand $\mathrm{J}$ Gastroenterol. mai 1999;34(5):524-8.

[14]. Bollen CM, Beikler T. Halitosis: the multidisciplinary approach. Int $\mathrm{J}$ Oral Sci. 2012;4(2):55-63

[15]. Panov VE. Oral Manifestations of Hepatitis C Virus. J IMAB - Annu Proceeding Sci Pap. 1 oct 2013;19(4):377-9.

[16]. Carrozzo M, Scally K. Oral manifestations of hepatitis C virus infection. World J
GastroenterolWJG. 2014 June 28;20(24):753443.

[17]. Alavian S-M, Mahboobi N, Mahboobi N, Karayiannis P. Oral conditions associated with hepatitis C virus infection. Saudi J Gastroenterol Off J Saudi Gastroenterol Assoc. 2013;19(6):245

[18]. Ali A, Zein NN. Hepatitis C infection: a systemic disease with extrahepatic manifestations. Cleve Clin J Med. Cleveland Clinic Foundation; 2005;72(11):1005.

[19]. Agbo-Godeau S, Guedj A. Mycoses buccales. EMC-Stomatol. Elsevier; 2005;1(1):30-41.

[20]. Baker PJ, Dixon M, Evans RT, Dufour L, Johnson E, Roopenian DC. CD4+ T cells and the proinflammatory cytokines gamma interferon and interleukin- 6 contribute to alveolar bone loss in mice. Infect Immun. Am Soc Microbiol; 1999;67(6):2804-9.

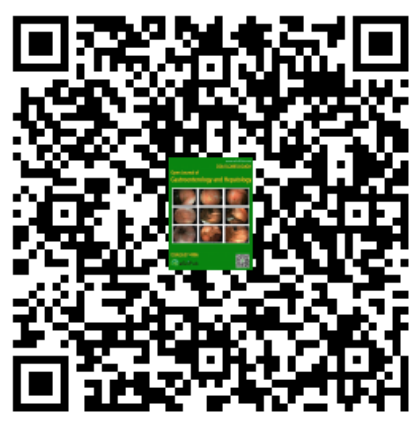

